\title{
Fantasy sports and gambling regulation in the Asia-Pacific
}

\author{
Muralee Das ${ }^{1}$ \\ Accepted: 5 August 2021 / Published online: 21 August 2021 \\ (c) T.M.C. Asser Instituut 2021
}

\begin{abstract}
Fantasy sports competitions allow sports fans to become their own managers, to select and organize fantasy teams from existing real-life players in professional sports leagues. The performance of their fantasy teams is dependent on the actual on the field performance of these real-life players. As betting in professional sports is strictly regulated worldwide, fantasy sports offer a form of proxy sports bet. However, a gray area exists whether fantasy sports competitions involve chance (or luck) rather than pure team selection skills. If any form of chance is involved, fantasy sports will be subject to gambling laws and thus may be deemed illegal. With the US Supreme court recently clearing the way for legality of fantasy sports in its largest market, the focus shifts to the industry's major growth market-Asia-Pacific. This paper reviews the state of fantasy sports and gambling regulation in the Asia-Pacific region. A 21-country analysis is undertaken, offering five insights for fantasy sports industry stakeholders. Based on our findings, we propose a Nevada-model regulatory framework for the Asia-Pacific fantasy sports market.
\end{abstract}

Keywords Fantasy sports $\cdot$ Asia-Pacific $\cdot$ Gambling laws $\cdot$ Sports betting

\section{Introduction}

Gambling or betting can be defined as an "agreement between two or more parties to deliberately stake something of value (typically money) with intent to profit on the outcome of an event that is determined wholly, or partially by chance." ${ }^{.1}$ In other words, punters are betting against uncertainty. Sports betting fits in this definition as sports match outcomes are to a large extent uncertain (chance), but the skill of the punter is necessary for interpreting and analyzing past performance analytics, which technically is akin to the skill of the casino gambler having access and using available published mathematical probabilities for casino games.

In the USA, sports betting had been illegal since 1992 under the Professional and Amateur Sports Protection Act (PASPA Act 1992) $)^{2}$. However those uncertainties ceased to exist ${ }^{3}$ in

\footnotetext{
${ }^{1}$ Pickering, Blaszczynski, Hartmann, and Keen 2016.

2 PASPA Act "grandfathered" existing sports betting for the states of Nevada, Montana, Delaware and New Jersey.
}

Muralee Das

muralee.das@maine.edu

1 Maine Business School, University of Maine, Orono, USA
2018 when the US Supreme Court ruled that the PASPA Act violated the American states' ability to legalize sports betting ${ }^{4}$. This landmark decision opened the floodgates for each American state to separately legislate on sports betting ${ }^{5}$.

With the legal position of sports betting now clear in the USA, the spotlight has shifted to the global markets. The world's largest online sports betting operator Draft Kings estimates that the global legal gambling (lotteries, bingo, casino, gaming machines/slots, lotteries and sports betting) market size is USD456 billion ${ }^{6}$. Sports betting as a segment represents $16 \%$ of that global market at USD72 billion ${ }^{7}$.

\footnotetext{
3 This should be qualified as there have been recent decisions by US courts that have reignited the uncertainty. In White v. Cuomo (181 A.D.3d 76 (N.Y. App. Div. 2020)). A New York Appellate Court ruled that daily fantasy sports was gambling despite New York legislators having amended the existing law after Murphy $v$ NCAA to exempt fantasy sport from gambling laws. In contrast in a recent Illinois Supreme Court case (Dew-Becker, 2020 IL 124472 25), it was ruled that daily fantasy sports is determined purely on skill. Clearly, the state-by-state legislation in America on sports betting will see further such conflicting verdicts for fantasy sports.

${ }^{4}$ Murphy v NCAA (2008).

5 As of November 1, 2020, 20 of 50 or $40 \%$ of US states have legalized sports betting https://www.espn.com/chalk/story/_id/19740480/ the-united-states-sports-betting-where-all-50-states-stand-legalization.

${ }^{6}$ DraftKings (2020) Analyst Day Presentation March 2020 https:// draftkings.gcs-web.com/static-files/f973bec8-59cb-43d5-9681-67656 6 ea5c6e.

7 Ibid.
} 
Still other market observers believe legal and illegal sports gambling worldwide is actually a USD3 Trillion industry ${ }^{8}$. Outside the USA, gambling is a massive growth industry in the Asia-Pacific. However, sports betting continues to be prohibited in most countries of the Asia-Pacific region with the exception of Australia, and with limited exception in Japan, Singapore, South Korea, New Zealand and Taiwan.

Despite that, regulators in the Asia-Pacific have begun to appreciate the possible advent of punters circumventing sports betting regulations and instead use a derivative of sports betting-fantasy sports-to indirectly bet on sport games. Fantasy sports allow participants to select players across the league to form their own fantasy teams. This fantasy team then "competes" with that of other such teams in fantasy leagues. The competition can be one season long or on a daily basis (daily fantasy sports or "DFS"). The actual performance of the fantasy team players in their own real-life teams is used to determine the performance of each fantasy team. The "winning" fantasy team is rewarded with cash or other forms of prizes. Sports analysts estimate fantasy sports is a USD18 billion global industry that is projected for exponential growth and become a USD48 billion market in $2027^{9}$.

Fantasy sports has existed within a gray area of regulation worldwide because there has been a strong argument that it is a game of pure skill rather than of chance, thereby falling outside the definition of gambling per se. The argument centers on the fact that fantasy sports teams are just exactly that-a fantasy, since they don't exist nor compete in real-life leagues. Therefore, there are no event or event outcomes of matches. The "winning" fantasy teams instead are the ones with highest collection of scores from fantasy player picks based on that players' individual performance. A successful fantasy team manager thus has to possess a high level of competency in analyzing past sports data to predict future player performance, much like a fund manager making stock selections.

The Asia-Pacific's current regulatory situation is similar to that in the USA post-Paspa Act and pre-Unlawful Internet Gaming Enforcement Act (UIGEA Act) $2006^{10}$, which was passed by Congress to regulate illegal online gambling. In the UIGEA Act, there were five exceptions ${ }^{11}$ which fitted with the characteristics of a fantasy sports competition-(i)

\footnotetext{
8 AFP, Global Sports Gambling worth up to 3 trillion, Daily Mail Australia (online), 16 April 2015,http://www.dailymail.co.uk/wires/ afp/article-3040540/Global-sports-gambling-worth-3-trillion.html. Accessed 15 September 2020.

9 Allied Analytics LLP Fantasy Sports Market Expected To Reach USD48.6 billion by $2027 \mathrm{https} / / /$ www.einnews.com/pr_news/52780 3935/fantasy-sports-market-expected-to-reach-48-6-billion-by-2027allied-market-research Accessed 15 September, 2020.

10 Scott 2016.

11 Standen 2016.
}

that winning was not linked to a single team performance or (ii) single athlete performance, (iii) that winning requires the skill of the participant to use collective statistical results, that (iv) prizes awarded are not proportionate to entry fees or participant numbers and (v) all prizes are communicated at the onset. In effect, with these kind of certainty, the UIGEA Act, helped the launch the fantasy sports industry in the USA. Further down the road though, the legal argument in the USA (prior to the 2018 Supreme Court decision to effectively legalize sports betting) was whether fantasy sports involved chance outcomes. After the UIGEA Act, each American state took different legal positions (i.e., skill or chance) showcasing the inherent complexities of regulating fantasy sports. The legal debate lasted until the 2018 Supreme Court decision, after which fantasy sports became a legitimate industry in the USA. In fact, the largest fantasy sports company Draft Kings transformed virtually overnight to become an online sports betting giant ${ }^{12}$.

Fantasy sports competitions in the Asia-Pacific thus far have avoided close scrutiny of law makers in the region compared to that of the USA. However, the rapid explosion of offshore online sports betting across Asia-Pacific and the entry of DraftKings into the region will surely bring the fantasy sports industry under the radar of Asia-Pacific policy makers and regulators. Importing lessons learned from the US debate, one would assume the pace in academic discourse to study implications of Asia-Pacific fantasy sports regulation would have resulted in an early understanding of legal and regulatory framework required for the region. However, with the exception of the Australian fantasy sports market, this has not been the case. Potential new market entrants, millions of fantasy sports participants, sports governing bodies, government stakeholders and lawmakers within the Asia-Pacific region are still struggling to have a wide lens perspective as to the legal status of the regions fantasy sports industry. Part of the reason for this, we believe, is the distrust and fear among Asia-Pacific lawmakers to legalize sports betting. However, as the US experience has demonstrated, legalizing sports betting automatically legitimizes the fantasy sports industry.

Thus, this paper will contribute in two ways: (i) one of the first articles to analyze the Asia-Pacific gambling market and build foundational knowledge of the Asia-Pacific sports betting and fantasy sports regulations and (ii) offer a potential future legal framework for fantasy sports regulation in the Asia-Pacific. Our purpose is to offer an article that is both descriptive and prescriptive: What is the current legal landscape for fantasy sports in the Asia-Pacific?

\footnotetext{
12 Axson S, DraftKings entering sports betting market after Supreme Court decision, Sports Illustrated (online), 14 May 2018, https:// www.si.com/more-sports/2018/05/14/draft-kings-betting-supremecourt-decision Accessed 16 September, 2020.
} 
Table 1 Gambling and fantasy sports regulation in the Asia-Pacific

\begin{tabular}{|c|c|c|c|c|c|}
\hline Country & $\begin{array}{l}\text { Gambling } \\
\text { permitted }\end{array}$ & $\begin{array}{l}\text { Land-based casinos } \\
\text { (licenses awarded) }\end{array}$ & $\begin{array}{l}\text { Legalized } \\
\text { sports betting }\end{array}$ & $\begin{array}{l}\text { Fantasy sports } \\
\text { regulation }\end{array}$ & Notes \\
\hline \multicolumn{6}{|l|}{ North Asia } \\
\hline China (Mainland) & No & No & Yes & No & \\
\hline China-Macau & Yes & Yes (40) & Yes & No & \\
\hline China-Hong Kong & Yes & No & Yes & No & \\
\hline Japan & Yes & Yes $(0)$ & Yes & No & \\
\hline South Korea & Yes & Yes (23) & Yes & Yes & Fantasy sports rewards must be non-cash \\
\hline North Korea & No & Yes (1) & No & No & \\
\hline Taiwan & Yes & No & Yes & No & \\
\hline Mongolia & No & No & No & No & \\
\hline \multicolumn{6}{|l|}{ South-East Asia } \\
\hline Malaysia & Yes & Yes (1) & No & No & \\
\hline Singapore & Yes & Yes (2) & Yes & No & \\
\hline Vietnam & Yes & Yes (8) & Yes & No & \\
\hline Cambodia & Yes & Yes (34) & No & No & \\
\hline Laos & Yes & Yes (2) & No & No & \\
\hline Myanmar & No & No & No & No & \\
\hline Philippines & Yes & Yes $\left(47^{*}\right)$ & No & No & *Excluding 40 offshore casino licenses \\
\hline Timor-Leste & Yes & Yes (1) & No & No & \\
\hline Thailand & No & No & No & No & \\
\hline Indonesia & No & No & No & No & Sharia law-Gambling prohibited \\
\hline Brunei & No & No & No & No & Sharia law-Gambling prohibited \\
\hline \multicolumn{6}{|l|}{ Oceania } \\
\hline Australia & Yes & Yes (13) & Yes & Yes & \\
\hline New Zealand & Yes & Yes (6) & Yes & Unclear & \\
\hline N (Asia-Pacific) & 14 & 13 (178) & 10 & 2 & \\
\hline
\end{tabular}

Bold values indicate the total count of positive cases ("Yes")

How do we create an Asia-Pacific fantasy sports industry with world-class regulation? To this effect, in conducting our analysis and offering a future framework, we are guided by the US state of Nevada's 70-year experience in regulating sports betting. Nevada was the first US jurisdiction to permit sports betting in its casinos and has a very rich and exhaustive regulatory blue print. In reviewing gambling legislation, specifically sports betting laws in the Asia-Pacific, we want to use the Nevada best practices as our filter. The former Chairperson of Nevada Gaming Commission Betty Harris's 2020 law article "Regulated Sports Betting: A Nevada Perspective" 13 outlined seven regulatory best practices for other jurisdictions:

Integrity is paramount in the game; sports betting will fail if the game itself is riddled with integrity legacy issues State-level jurisdiction is supreme to federal-level laws; "Tax Rates and Fee Structures Can Dramatically Influence Both the Legal and Illegal Sports Betting Market."

$\overline{13}$ Harris 2020.
The price to enter the bet is an important consideration for punters to choose between using licensed bettors or illegal bettors.

"Government Mandates Are Not Necessary." Economics should dictate the relationship between sports governing bodies and sports betting operators

Illegal punters are here to stay, so enforcement must be ongoing despite regulation

"Sports Wagering and Its Technology Needs to Maintain the Highest Standards of Integrity, Accountability, and Regulatory Compliance." There must be oversight in gaming infrastructure and technology to maintain confidence.

Consumer gaming protection. There must be a comprehensive plan for problem gambling

Here is our roadmap: The paper organizes the larger AsiaPacific consisting of 21 countries into three regions: North Asia, South-East Asia and Oceania. See Table 1. We first consider the state of gambling regulations in each of the AsiaPacific countries, focusing on (a) land-based casinos, because 
of their significant impact on gambling legislation and public opinion on gambling and (ii) sports betting because the past US legal debate showcased the narrow interpretation of lawmakers between sports betting and fantasy sports.

Where specific country legislation exists for fantasy sports, we will investigate the specifics of that law. To provide a more robust analysis, our in-depth focus is on five countries with large gambling markets, that allow sports betting and with advanced gambling legislation-Australia, Japan, Singapore and New Zealand. The final two sections discuss policy recommendations for the Asia-Pacific region and a future research agenda.

\section{Asia-Pacific gambling market}

\subsection{North Asia}

The North Asia region consists of China (including Hong Kong and Macao), Japan, South Korea, North Korea, Taiwan and Mongolia. Gambling has strong cultural heritage especially among the majority Chinese population of the region. As discussions in later parts of the paper will highlight, the Chinese gambling patron (particularly for casino gambling) has had significant influence on the growth and sustainability of the Asia-Pacific gambling industry.

\subsection{China, Hong Kong and Macao}

Gambling activities (including online betting ${ }^{14}$ ) are illegal in China, except in the Special Administrative Regions (SAR) of Hong Kong and Macau. In Mainland China, there are two exceptions in the form of state-run lotteries called the Welfare Lottery and the Sports Lottery ${ }^{15}$. The Chinese Sports Lottery is the only form of sports betting in mainland China, as it allows punters to place wagers on international football match results. The Chinese Sports Lottery is the second largest lottery in the world with reported sales of $\$ 16$ billion in 2018. ${ }^{16}$

\footnotetext{
${ }^{14} \mathrm{Ha} \mathrm{K}$, Hong J \& Calonzo A, The \$24 billion online casino boom China is struggling to halt, Bloomberg (online), 12 September 2019, https://www.bloomberg.com/news/articles/2019-09-11/the-24-billiononline-casino-boom-china-is-struggling-to-halt Accessed 1 October 2020

15 The Economist, The Chinese state manages the world's second biggest lottery industry, The Economist (online), 31 August 2019, https://www.economist.com/china/2019/08/29/the-chinese-statemanages-the-worlds-second-biggest-lottery-industry Accessed 1 October 2020

16 Rick A,World's Second Largest Lottery-In China-is set to become even bigger, FORBES (online), 30 May 2018, https://www. forbes.com/sites/augustrick/2018/05/30/the-worlds-second-largestlottery-in-china-is-set-to-become-even-bigger/?sh=69a521a46355 Accessed 1 October 2020.
}

The SAR of Hong Kong was a Chinese territory leased to Britain between 1887 and 1997, and when it reverted to China, there was an agreement to keep the British administrative model and legal framework intact for another 50 years. Hong Kong's gambling legislation is the Betting Duty Ordinance Cap. 108 and Gambling Ordinance Cap. $148^{17}$. Existing Hong Kong laws allow sports betting on horse racing and football, although one licensee (Hong Kong Jockey Club) is the monopoly operator. The Gambling Ordinance 2002 is the specific legislation that is used to regulate online sports betting, which remains illegal in Hong Kong. Fantasy sports organizers should be wary of the Gambling Ordinance Cap where if there is chance element in a prize promotion, then that activity requires approval.

SAR of Macau is the only Chinese territory that allows casino gambling. Casinos though were approved not by the Chinese government but rather its Portuguese administration, which had leased Macau from 1899 until 1999. Similar to the case of Hong Kong, upon Macau reverting to Chinese rule, there was an agreement for all existing laws in Macau to be intact for another 50 years. Interestingly, during their 100-year rule, the Portuguese government only awarded a monopoly casino license in 1961 to Sociedad de Turismo e Diversoes de Macau SA (STDM) owned by the late Hong Kong billionaire "Asian king of gambling" Stanley $\mathrm{Ho}^{18}$. Just 2 years after Macau returned to Chinese sovereignty in 1999 , this monopoly was dismantled in 2001 through new legislations. The Macau Gaming Law (Law No.16/2001) and Administrative Regulation No.26/2001 were enacted to award gaming concessions. As a result, today there are now 40 casinos operating in Macau, and it is the world's largest gambling hub ${ }^{1920}$. Access by the mainland Chinese population to gamble in Macau, casinos, however, are restricted through the need for travel visas to enter Macau. Similar to mainland China and Hong Kong, online gambling is prohibited in Macau. To curb illegal gambling and betting, Macau has enacted Law No.8/96/M also known as the Illegal Gaming Law.

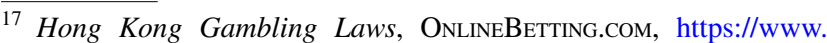
onlinebetting.com/legal/hong-kong/ . ACCESSED 25 SePTEMBER 2020.

18 BBC, Stanley Ho, Hong Kong's "king of gambling" dies aged 98, BBC (online), 26 May 2020, https://www.bbc.com/news/business52803396 Accessed 10 October 2020.

19 Sito P, Li P and Liu Y (2020) Stanley Ho patriarch of Asia largest casino empire and the "King of Gambling" for more than half a century dies at 98, South China Morning Post (online), 26 May 2020 https://www.scmp.com/business/companies/article/2182745/stanleyho-patriarch-asias-largest-casino-empire-and-king Accessed 10 October,2020.

${ }^{20}$ Zabielskis 2015.
} 


\subsection{Japan}

The Japanese gambling industry has strong government and cultural roots. Japanese regulators have been very liberal in historically allowing sports betting for horse racing ("Keiba"), local football matches (J-League Sports Toto), cycling races ("Keirin"), motor-racing and speed boat ("kyotei") competitions ${ }^{21}$. The legislative compromise is that all races are run by government-owned organizations, thus according a form of controlled gambling. The exception is the Japanese pinball equivalent chance entertainment game of "Pachinko," a favorite cultural past time in the country. It is the biggest chance-based "gambling" contest allowed that is not regulated, only because the winnings are in the form of tokens. ${ }^{22}$. These winning tokens are exchanged with cash, either at the Pachinko centers or independent token vending machines. Interestingly, Pachinko game centers also host gambling slot machines ${ }^{23}$. Online sports betting remains illegal in Japan. ${ }^{24}$

In 2016, the Japanese parliament (“diet”) passed legislation for casino gaming licenses ${ }^{2526}$, modeled as Integrated Resorts, and known as the Integrated Resorts Act ${ }^{27}$. The highly controversial law limits the number of licenses to just three operators, with a maximum of 15 years tenure each (10-year initial license and renewal for another 5 years), then subject to subsequent renewal approval from local authorities. Further, while the casinos will be open to foreigners, entry is restricted by frequency to Japanese citizens. However, even though the first casinos are not scheduled to operate until 2025, opposition has been fierce within the

\footnotetext{
21 Yasko N , Japanese Gambling, https://www.japanvisitor.com/japan ese-culture/cult-japan-gambling Accessed 10 October 2020.

${ }^{22}$ Hiro K (2020)Gambling in Japan: 7 Best Ways to Gamble without a casino, JW Magazine (online), 20 Jan 2020, https://jw-webma gazine.com/gambling-in-japan-best-ways-to-gamble-without-casino/ Accessed 10 October 2020

${ }^{23}$ Lewis L, Odds are against pachinko staying clear of gambling rules: Inside Business Asia. Financial Times (online), 13 December 2017. https://www.ft.com/content/1a273dd6-df41-11e7-a8a4-0a1e6 3a52f9c. Accessed 10 October 2020.

${ }^{24}$ Yamamoto T (2019) Fantasy sports gaining Japan foothold with basketball the first step, IAG https://www.asgam.com/index.php/ 2019/05/03/fantasy-sports-gaining-japan-foothold-with-basketballthe-first-step/.

${ }^{25}$ Soble, J., \& Gough, N. (2016). Japan, envisioning billions in revenue, removes ban on casino gambling. New York Times (online) Retrieved from https://library.umaine.edu/auth/EZproxy/test/authej. asp?url=https://search.proquest.com/docview/2310050925?accou ntid=14583 Accessed 10 October 2020

${ }^{26}$ Sugiura E (2018) Five things to know about Japan's new casino law, Nikkei (online) https://asia.nikkei.com/Business/Business-trends/ Five-things-to-know-about-Japan-s-new-casino-law2 Accessed 10 October 2020

27 McCartney 2016.
}

Japanese public, largely through fears of underworld crime involvement. In 2018, to placate these growing public opposition to the $I R$ Act, legislation spelling strict operational requirements for these three future casinos were enacted with the passing of the Specified Tourist Complex District Development Act (The Development Act) ${ }^{28}$. The 2020 pandemic and the resignation of the casino law's most influential political champion, former Prime Minister Shinzo $\mathrm{Abe}^{29}$ in August 2020, have resulted in severe slowing down of the bidding process for these casino licenses.

\subsection{South Korea}

There are 23 land-based casinos in South Korea ${ }^{30}$, all but one for foreigners catering primarily to tourists from neighboring China and Japan. Sports betting is permitted ${ }^{31}$ for seven types of sports through a lottery system. Sport betting was legislated in 2001 via the National Sports Promotion $\mathrm{Act}^{32}$. The monopoly for sports betting is run by KToto $\mathrm{Ltd}^{33}$. Fantasy sports platforms have been allowed to operate as long as there is no monetary rewards. One-way operators have been able to circumvent this is to offer "tokens" as a form of currency. The French blockchain-based fantasy sports company Sorare recently inked an agreement with the South Korean Football Association to have the latter's players featured in fantasy league playing cards. The cards are purchased from Sorare, but the fantasy league participants are not betting on games. Rather the cards become collectors' tokens and derive its value from scarcity. ${ }^{34}$

\subsection{Taiwan, North Korea and Mongolia}

In Taiwan, sports betting is allowed through the Sports Lottery which allows wagers in US Major League Baseball and

\footnotetext{
${ }^{28}$ Hernandez-Diaz 2020.

${ }^{29}$ Lewis, L. (2018). Japan's Abe poised to raise stakes in casinos gambit: Travel \& leisure coalition parties to review gambling law after years of corporate lobbying [asia region]. Financial Times (online), Retrieved from https://library.umaine.edu/auth/EZproxy/test/ authej.asp?url=https://search.proquest.com/docview/2023843667? accountid=14583 Accessed 10 October 2020.

${ }^{30}$ https://www.hapskorea.com/south-koreas-complex-relationshipwith-gambling/ Accessed 15 September 2020

31 Ibid.

32 http://www.ktoto.co.kr/en/s2_binfo/binfo01.html Accessed 15 September 2020.

${ }^{33}$ Ibid.

${ }^{34}$ Kalra J, South Korean Soccer League tokenizes players for fantasy football game, Yahoo (online), 18 June 2020. https://uk.news. yahoo.com/south-korean-soccer-league-tokenizes-000000701.html? guce_referrer $=$ ahr0chm6ly93d 3 cuz29vz2xllmnvbs $8 \&$ guce_referrer_ sig=aqaaaf_mn2og3ss4ujq3tifvudr-i93o4q_wkuoigoo4u-rpc2lkj9yl q5rcrbyehpqh14ac-hkjzncrxz4yrtcj2ifpzvdnrf1q1fonhmcanpdtrn-5rfkxey9uylkesxejqx8maeac5bzwkbg4bq9f0qr5keaid6f8iuwsspwa-xt Accessed 10 October 2020.
} 
National Basketball Association matches. The Sports Lottery Issuance Act gives monopoly rights to Fubon Bank to run the lottery. In North Korea, Sociedad de Turismo e Diversoes de Macau SA (STDM) or SJM Holdings, the Macaubased casino operator, runs North Korea's only casino at Yanggakdo International Hotel in the capital Pyongyang ${ }^{35}$. Ironically for an isolated country, the sole casino is open only to foreigners presumably from bordering China. There are no other gambling or sports betting operations in North Korea. For Mongolia, we could not find evidence of official gambling legislation or operations.

\section{South-East Asia}

South-East Asia consists of Malaysia, Singapore, Indonesia, Brunei, Timor-Leste, Thailand, Myanmar, Vietnam, Laos, Cambodia and the Philippines. The countries of the region are part of a political and economic bloc known as Association of South East Asian Nations (ASEAN). ASEAN has considerable economic clout with a population (consumer) size of 600 million people. There are flexible visa-free travel between ASEAN member countries, which is a major convenience for cross-border gambling tourism.

\subsection{Singapore}

Influenced by its past status as a British colony (until 1957), Singapore has traditionally allowed betting on horse racing, a staple of upper class British society. The Singapore Totalisator Board is the enforcing agency for pools betting, while Singapore Pools runs the monopoly state lottery.

In 2006, the Singapore government recognizing the need to re-invent and re-position the island republic into a tourism hub took the radical step to approve casino operations through the Casino Control Act and regulated by the Casino Regulatory Authority. After an international tender exercise in 2010, two casino licenses (which were identified as "Integrated Resorts ${ }^{36 "}$ much like the Las Vegas casino resort model) were awarded to Malaysian casino operator Genting Group on nearby Sentosa Island, and the other license to the US based Las Vegas Sands. In exchange for investment to expand its operations, the government in 2019 extended the two casino licenses until $2030^{37}$.

\footnotetext{
$\overline{35}$ O'Connor D (2020) North Korea casino, ski resorts, tourism goals tumble, climate change to blame, casino.org, https://www.casino.org/ news/north-korea-casino-ski-resorts-tourism-goals-tumble/ Accessed 11 October 2020.

36 Zhang 2017.

37 Straits Times, Singapore considers tightening casino rules for customers, Straits Times (online),20 July 2020. https://www.straitstimes. $\mathrm{com} /$ business/economy/singapore-considers-tightening-casino-rulesfor-customers, Accessed 5 June 2021
}

Until 2014, sports betting in Singapore had been regulated by the Betting Act. To curb the onslaught of overseas based online sports betting sites, the Singapore government's response was through a specific law that prohibited such activity except where it is licensed. Thus in 2015, the government enacted the Remote Gambling $A c t^{38}$, which imposes fines and jail-terms for both users and service providers. The Singapore Ministry of Home Affairs enforces the Remote Gambling Act (RGA). In 2016, two licenses (Singapore Pools and Singapore Turf Club) were awarded for online sports betting in Singapore ${ }^{39}$. However, the Remote Gambling Act has been unable to attract the impact it probably intended to deter online sports betting. In fact, the Singapore Courts have been reluctant to impose hefty sentences under the Remote Gambling Act for first time sports betting offenders arguing in a 2019 case that: "The solution, it would seem, lies with Parliament to either increase the maximum fine to better deal with such situations, or to allow for fines to be coupled with other orders, including instruction and education on responsible gambling." 40

The Remote Gambling Act interestingly included a carve out exemption, similar to the US UIGEA Act, for games not purely determined by chance. Unlike the US law, such an exemption in Singapore's Remote Gambling Act has not yet been "legally tested" by fantasy sports operators. But because Singapore legislators had an almost 10-year hindsight benefit of observing uncertain and chaotic legal debate in the USA after the UIGEA Act came into effect, it may not be risky to take the position that Singapore lawmakers were intending on fantasy sports to be classified as a game of skill. A recent development for 2021 is the proposed consolidation of regulatory agencies into the Gambling Regulatory Authority (GRA) $)^{41}$, a prelude to a review of gambling laws in Singapore. This review may further clarify the carve out and confirm the status of fantasy sports in Singapore.

\footnotetext{
$\overline{38 \text { Parliament }}$ of Singapore, Remote Gambling Act Singapore, https:// www.parliament.gov.sg/sites/default/files/Remote\%20Gambling\% 20Bill\%2023-2014.pdf. Accessed 15 October 2020.

39 Cheong D and Lin M, Online betting to be allowed in next two months via Singapore Pools and Singapore Turf Club', Straits Times (online), 29 September 2016,, http://www.straitstimes.com/singa pore/online-betting-to-be-allowed-in-next-two-months-via-singaporepools-singapore-turf-club Accessed 15 October 2020.

40 Vijayan K C, Jail Inappropriate for first time remote gaming offence: Courts, Straits Times (online) 25 November 2019, https:// www.straitstimes.com/singapore/courts-crime/jail-inappropriate-forfirst-time-remote-gambling-offence-court Accessed 9 June 2021.

41 https://www.casinonewsdaily.com/2020/09/24/singapore-confi rms-2021-establishment-of-new-gambling-regulator/ Accessed 5 June 2020.
} 


\subsection{Malaysia}

Malaysia is a Muslim country but with a sizeable nonMuslim population ${ }^{42}$. Even though Islam forbids gambling, Malaysia's unique demographics have historically resulted in a political compromise when it comes to gambling approvals and regulation. There are four gambling laws in Malaysia: Common Gaming Houses Act, 1953 Lotteries Act 1952, Betting Act 1953, and Pool Betting Act 1967. These laws in effect limit the issuance of gambling licenses to non-Muslim entities. For example, the single casino operator is an ethnic majority Malaysian Chinese-owned Genting Highlands Resorts of the Genting Group ${ }^{43}$. To avoid constant public scrutiny, the casino resort is located on a windy hill far from any major city. Similar to neighboring Singapore, because of Malaysia's British colonial history, horse races have been traditionally held weekly across Malaysia ${ }^{44}$ with an implied moral self-regulation that they are off-limits to Muslims. That's because the results of these weekly races are used to determine select lottery results. Malaysia licenses six large private lottery operators, all owned by ethnic Malaysian Chinese - the three largest being Berjaya Sports Toto, Magnum 4-D and Pan Malaysian Pools (Da Ma Cai) ${ }^{45}$. Legal analysts have lamented that Malaysia's existing gaming laws (all enacted prior to 1970) cannot police online gambling such as sports betting, ${ }^{46}$ because the laws don't cover internet gambling or online bets.

\subsection{Vietnam}

Vietnam has a medium-sized casino gambling industry with eight casinos ${ }^{47}$, but they are mostly foreigner entry only resorts, though there have been recent relaxations based on the financial strength of the casino. In 2018, through a government decree (Decree No.06/2017/ND-CP), the

\footnotetext{
$4239 \%$ of Malaysia's population is non-Muslim, See https://www.cia. gov/the-world-factbook/countries/malaysia/ .Accessed 9 June 2021.

43 Genting Group profile https://www.genting.com/history-2/ Accessed 9 June 2021.

44 https://www.malayan-racing.com Accessed 9 June 2021.

Horse racing was a legacy of the British who colonized Malaysia (or Malaya at that time). Horse racing in Malaysia began in 1802.

${ }^{45}$ Lim J, Number forecast operators' close outlets in MCO areas. The Edge (online), 13 January 2021. https://www.theedgemarkets.com/ article/numbers-forecast-operators-close-outlets-mco-areas Accessed 9 June 2021.

${ }^{46}$ Chua E, Current gambling laws lack bite, The Star (online), 29 Oct 2020, https://www.thestar.com.my/news/nation/2020/10/29/currentgambling-laws-lack-bite Accessed 1 June 2021.

47 Cohen M, How Vietnam is Changing its gambling rules to win foreign investment, FORBES (online), 9 Feb 2017, https://www. forbes.com/sites/muhammadcohen/2017/02/09/how-vietnam-is-chang ing-its-gambling-rules-to-win-foreign-investment/?sh=98e8b630e7aa Accessed 15 October 2020
}

government allowed a pilot 5-year law allowing sports betting on horses, greyhound racing and international football ${ }^{48}$.

\subsection{Cambodia}

The first casino approved in Cambodia was the Malaysianowned Naga World Resorts in 1999. ${ }^{49}$ However, since then the boom in the Cambodian gambling market has been significantly influenced by tourists' arrivals from China. For example, the Cambodian city of Sihanoukville has been one Asia's rising gambling hotbeds almost exclusively catering to the Chinese market. An astounding 193 casinos licenses have been issued (including online casinos) in Cambodia, with gambling legislation only recently enacted in $2020^{50}$. In tighter enforcement moves prior to the legislation and partly pressured by the Chinese government, the Cambodian government banned all online gambling, resulting in significant impact in the local gambling market. As a result, the number of actively operating casinos shrank from 76 to 34 operators by the end of $2019^{51}$.

\subsection{Laos}

There are two Chinese- or Macau-owned casinos operating in Laos ${ }^{52}$. Similar to the Cambodian market, both casinos cater exclusively to Chinese tourists from across the Chinese border. The first casino to operate was King Romans, while Savant Vegas is the latest operator. The Laotian authorities recently unveiled plans to increase gambling tax or levy up to $50 \%$ of revenues, signaling tighter future regulations ${ }^{53}$.

\subsection{Myanmar}

Myanmar (formerly known as Burma) has a very complicated political environment. For starters, the country is

\footnotetext{
${ }^{48}$ Das K (2018) Vietnam Legalizes Sports Betting, Vietnam Briefing (online), 20 June 2018. https://www.vietnam-briefing.com/news/vietn am-legalizes-sports-betting.html/. Accessed 12 October 2020.

49 Yamada 2017.

50 Strangio S, Cambodia passes law to regulate exploding gambling sector, The Diplomat (online), 7 October 2020, https://thediplomat. com/2020/10/cambodia-passes-law-to-regulate-exploding-gamblingsector/ Accessed 15 October 2020.

51 Thul PC, Thousands lose jobs, casinos shut as Cambodia bans online gambling, Reuters (online), 31 December 2019, https://www. reuters.com/article/us-cambodia-gambling/thousands-lose-jobs-casin os-shut-as-cambodia-bans-online-gambling-idUSKBN1 YZ0O3 Accessed 15 October 2020.

52 Sims 2017.

53 Silverstien E (2019) Laos looks to increase levies on gaming as national economic conditions marginally improve, Casino.org, 26 June 2019. https://www.casino.org/news/laos-looks-to-increase-levies-on-gaming-as-nations-economic-conditions-marginally-improve/ Accessed 18 October 2020.
} 
in transition from an almost 50-year military rule into a democracy ${ }^{54}$. Elections have been held but Myanmar suffers from deep legacy of ethnic and religious fault lines ${ }^{55}$ that has even overlapped into gambling laws. There are fractured and renegade provinces still under the command of rebel forces opposed to the either the military rulers or new democratic parties ${ }^{56}$. Casinos were legalized in $2018^{57}$, but this served as another vehicle to facilitate political corruption. Myanmar's rulers have used the grant of casino licenses as a form of bargaining chip with rebel forces. The widely reported example is that of the USD15 billion new development known as Yatai City ${ }^{58}$, where in exchange for casino approvals to rebel forces, the latter agreed to assimilate back into society. Nevertheless, the "rulers" of renegade provinces such as Yatai and Shan Province have reportedly used cryptocurrency to shield alleged money laundering operations, creating international financial crime issues for Myanmar.

\subsection{Philippines}

Gambling is a major growth industry in the Philippines including a thriving online gambling sector ever since more of such licenses began to be issued in 2016 by the liberal policies of President Duterte's Administration. There are a reported 40-60 online casino operators (known as Philippines Online Gaming Operators [POGO]), engaging in proxy betting in the Philippines ${ }^{59}$. Proxy betting is wagers placed by offshore punters (almost exclusively from China) in legal online casinos. A majority of these POGOs are essentially Chinese-owned casinos operating in the Philippines. The local authorities were pressured recently by the Chinese government to crackdown on these online casinos as they facilitate illegal money outflows from the Chinese mainland. There are at least 47 licensed land-based casinos operating in the country, including 43 owned by the national casino regulator ${ }^{60}$. As the pandemic drastically reduced

\footnotetext{
54 Stokke and Aung 2020.

55 Aung 2020.

56 Bünte 2021.

57 Nitta Y, Myanmar to probe casinos in China backed developers rogue city, Nikkei Asia(online), 12 August 2020. ,https://asia.nikkei. $\mathrm{com} /$ Spotlight/Belt-and-Road/Myanmar-to-probe-casinos-in-Chinabacked-developer-s-rogue-city Accessed 15 October 2020.

58 Ibid.

59 Alegado S and Calonzo A, Pandemic threatens to burst Philippines online gaming bubble, Bloomberg (online), 17 July 2020. https:// www.bloomberg.com/news/articles/2020-07-16/pandemic-threatensto-burst-philippines-online-gaming-bubble Accessed 15 October 2020 .
}

land-based casino tax revenues, the Philippines in December 2020 approved three casinos in the capital of Manila to offer online sports betting in the form of horse racing and cockfighting ${ }^{61}$.

\subsection{Timor-Leste}

After gaining independence in 1998 (through a public referendum) from Indonesia, Timor-Leste struggled to find new forms of economic revenue streams. While it negotiated for oil drilling concession rights with neighboring Australia, Timor-Leste explored with awarding casino licenses. In 2016, the Malaysia-based public listed slot machine maker RGB International submitted the first application for a casino license paying a USD200,000 deposit, only to face delays in license issuance. RGB subsequently withdrew their application ${ }^{62}$. However, Timor-Leste recently awarded the country's first casino license to the Golden Sands Dili ${ }^{63}$.

\subsection{Thailand, Indonesia and Brunei}

There are no legal gambling operators in these three countries. Gambling has been prohibited in Thailand since 1935 primarily under the Gambling Act BE 2478 (1935). Brunei and Indonesia are sharia law countries and prohibit any form of gambling. Those who are found to be gambling are imprisoned or fined.

\section{Oceania}

The Oceania region consists of all the Pacific Ocean island nations (i.e., Fiji, Tuvalu, Nauru, New Caledonia, Samoa, American Samoa, Kiribati, Solomon Islands Vanuatu, French Polynesia, Saipan, Northern Mariana Islands, Guam), Papua New Guinea ${ }^{64}$, New Zealand and Australia. For the purposes of this paper, we will focus on Australia

\footnotetext{
$\overline{60}$ O’Connor D, Casino.org, 29 April 2020, https://www.casino.org/ news/philippines-casino-revenue-drops-50-percent/ Accessed 1 June 2020.

${ }^{61}$ Venzon C, Philippines bets on online casino, e-cockfights, as Chinese flee, Nikkei Asia (online), 8 December 2020, https://asia.nikkei. com/Business/Media-Entertainment/Philippines-bets-on-online-casin os-e-cockfights-as-Chinese-flee Accessed 5 June 2021.

62 The Star, RGB Shelves Plan to enter Timor Leste Gaming History, The Star (online), 25 July 2015. https://www.thestar.com.my/Busin ess/Business-News/2015/07/25/RGB-shelves-plan-to-enter-Timor Leste-gaming-industry.

${ }^{63}$ https://timorplaza.com/stores/golden-sands-casino Accessed 15 October 2020.

${ }^{64}$ Papua New Guinea passed a Gaming Control Act in 2007 which can grant casino licenses but there are no casinos in operation as of 2020 .
} 
and New Zealand for two reasons. The first is the small population size of the Pacific Island nations wound render any sports betting market to be a very minor industry. Second, the Australian and New Zealand sports betting markets are very mature industries able to offer deeper insights for fantasy sports regulatory models elsewhere.

\subsection{New Zealand}

New Zealand's Department of Internal Affairs is the national gambling regulator. Gambling Act 2003 and Racing Act 2003 are the two laws that regulate gambling and sports betting in the country ${ }^{65}$. To better control sports betting, only two government-linked organizations- - the New Zealand Racing Board (NZRB) and Lotto New Zealand, are allowed to offer sports betting and online sports betting within the country. Interestingly, offshore betting operators while they cannot market their products in New Zealand may offer wagers to New Zealanders. Online betting from within New Zealand placed with NZRB has recorded a $60 \%$ growth in turnover between 2017 and 2019, while citizens spent about NZ\$300 million placing offshore bets during the same time period ${ }^{66}$.

Fantasy sports operators, however, may be caught out through the prohibition of interactive gambling in the Gambling Act 2003, but fantasy sports competitions may escape the legislation. For example as part of the guidance on the Act, the New Zealand Department of Internal Affairs offers this explanation ${ }^{67}$ :

If any competition involves "gambling" and there is consideration paid to enter then it will breach the prohibition on remote interactive gambling. Where a competitor chooses or selects winners for future games or sporting events this generally involves some element of chance as well as skill. If entry is genuinely free it will not be caught by the Act. If there is some consideration or more than a true communication cost then this type of competition will be caught by the Act.

\footnotetext{
65 https://sportnz.org.nz/media/2744/regulatory-impact-statementsport-nz-sports-betting-apportionment-formula.pdf Accessed 15 October 2020

66 Towle M, New Zealanders are pouring money into online gambling, The Stuff (online), 20 August 2019, https://www.stuff.co.nz/ business/industries/115129052/new-zealanders-are-pouring-moneyinto-online-gambling Accessed 15 October 2020.

${ }^{67} \mathrm{https} / / / \mathrm{www}$.dia.govt.nz/diawebsite.nsf/wpg_URL/ServicesCasino-and-Non-Casino-Gaming-Remote-Interactive-Gambling-andthe-Gambling-Act-2003?OpenDocument Accessed 18 October 2020.
}

If this explanation of the intention of the law is strictly interpreted, fantasy sports team selection (which is a skill) can be allowed, as it is not selecting winners or winning events, but rather the performance of individual real-life players. In addition, the Gambling Act 2003's subsidiary rules, the Gambling (non-gambling activities) Regulation $2013^{68}$, offers a test for certain spot competitions to be deemed not gambling in that they (i) connected to the competition up to 7 days post-event, (ii) "subsidiary to the competition or event" and (iii) a one-time consideration is paid. Daily Fantasy Sports can arguably pass all three tests, but there is an explicit reference to spot competition in the regulation as "lotteries." So there exists a future legislative potential to amend these regulations and remove the definition of spot competitions and thus paving way for possible legalizing of fantasy sports games in New Zealand.

New Zealand also hosts six land-based casinos first approved through the Casino Control Act 1990, although further issuance of casino licenses was curbed with the Gambling Act $2003^{69}$. Under the same law, casinos cannot offer internet gambling to local citizens.

\subsection{Australia}

Australia has one of the world's largest, most liberal and most regulated gambling markets. For a nation of just over 25 million people, the level of gambling on a per capita basis is incredible. The New York Times reported in $2018^{70}$ that Australian losses on gambling per capita are double that of the US population at USD18.4 billion. Australia is also home to 13 land-based casinos. Gambling is regulated at the state and territory level ${ }^{71}$ in Australia. As of 2020, there are 134 different gambling laws (including amendments) across all states and territories ${ }^{72}$. There is legal precedent that a gambling law once approved in a state or territory is applicable across at the federal Australia wide level ${ }^{73}$. This precedent has resulted in a limited form of "jurisdiction shopping,"

\footnotetext{
$\overline{68}$ https://www.legislation.govt.nz/regulation/public/2013/0392/latest/DLM5618506.html?search=ts_act\%40bill\%40regulation\%40dee medreg_gambling_resel_25_a\&p=1 Accessed 9 June 2021.

${ }^{69}$ https://www.dia.govt.nz/diawebsite.nsf/Files/GamblingFactShe ets-18Nov2015/\$file/FactSheet28-Oct2015.pdf Accessed 18 October 2020.

70 Baidawi A (2018) Australians are the world's biggest gambling losers and some seek action, New York Times (online), 4 April 2018. https://www.nytimes.com/2018/04/04/world/australia/australiansgambling-betting-machines.html Accessed 15 October 2020.

71 There are six Australian states- Victoria, New South Wales, South Australia, Tasmania, Western Australia, Queensland, two major territories-Australian Capital Territory and Northern Territory. Other territories include Norfolk Islands and Christmas Islands.

72 https://uk.practicallaw.thomsonreuters.com/w-022-4995?transition Type $=$ Default $\&$ contextData $=($ sc. Default $) \&$ firstPage $=$ true.

${ }^{73}$ Betfair Pty Ltd and Anor v Western Australia (2008) 244 ALR 32.
} 
in that new betting operators have chosen to incorporate and seek gambling licenses in more flexible and gambling friendly geographies such as the Northern Territory. Such a strategy was not lost on two of Australia's pioneering fantasy sports operators-Moneyball and PlayUp (formerly operating as TopBetta)—who are both licensed by the Northern Territory Racing Commission ${ }^{74}$.

Despite this, the advent of offshore gambling sites into Australia resulted in federal legislative response. The Interactive Gambling Act 2001 (Cth) and Interactive Gambling Amendment Act 2017(Cth) were enacted to regulate online gambling. Specifically the law prohibited online gambling that involved all contests that included chance or a mix of chance or skill, rewarded with cash prizes, required entrance fees to play and even bets between online platform participants. Still, to facilitate online betting by Australian onshore incorporated betting operators such as TAB Australia, the law exempted betting on "sports events." As a result, a large number of sports bets are placed online in Australia and signaled regulatory comfort in allowing fantasy sports operators such as Moneyball ${ }^{75}$ and PlayUp. As previously noted ${ }^{76}$, a further signal of implicit regulatory approval for fantasy sports betting was when Australian-owned and Australianbased fantasy sport operator Playup's predecessor TopBetta received approval in 2015 to list on the Australian Stock Exchange $^{77}$.

In contrast, leading Australian legal practitioners are unconvinced that the "sports event" exemption strictly includes fantasy sports because betting on fantasy sports is dependent on player performance (across many teams) rather than outcome of that players' specific team performance (a match event) ${ }^{78}$. To overcome this legal gray area and to preempt a future legislative tilt, existing fantasy sports operators seem to have hedged their legal position by partnering with Australian sports governing bodies, strengthening the argument that fantasy sports increases fan interest in the sports leagues and thus legal sport betting. This in turn besides positively advocating for the societal and sports industry benefits of encouraging fantasy sports contests and increases government tax revenues.

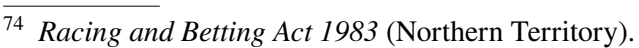

75 Tony Boyd, Moneyball the new sporting fantasy, Australian Financial Review (online), 4 September 2015, http://www.afr.com/brand/ chanticleer/moneyball-the-new-sporting-fantasy-20150904-gjfkw5. Accessed 15 October2020.

76 Das 2018.

77 See ASX announcement, TopBetta- Australia's First Fantasy Wagering Business to List on ASX, (2015), http://om-corporate. mugbookie.com/wp-content/uploads/2016/11/TopBetta_Lists_on_ ASX.pdf. Accessed October 5, 2020.

78 https://www.gtlaw.com.au/insights/regulation-fantasy-sports-austr alia-why-law-reform-required.
}

\section{Overview}

Our review of the legal and regulatory landscape of the Asia-Pacific fantasy sports industry, covering 21 countries, offers five important insights for stakeholders. The first insight is that contrary to common perception, legal sports betting is available in a third of countries (nine countries) in the Asia-Pacific region. As in most cases, there exists a hierarchy of such product or bet offerings in these various national markets. Australia and New Zealand jointly head the hierarchy, by allowing sports bets in all major sporting codes. Japan occupies the second rung with punters able to bet on five sporting events-the local football league (J-League) matches, horse racing, auto-racing, cycle racing and speedboat racing. Taiwan, South Korea, Singapore and Hong Kong take the middle positions of the hierarchy by sanctioning bets on a few major sports (including overseas leagues). For example, Taiwan's gambling laws approve bets on American baseball and basketball matches, while Singapore and Hong Kong residents are able to bet on horse racing and international football matches. At the bottom of the rung is Malaysia and China. Malaysia offers horse racing bets, while Chinese sports betting is limited to international football matches through a state lottery. Collectively, these nine jurisdictions have established laws regulating sports betting, which may signal regulatory acceptance of fantasy sports to coexist. Our analysis shows this is the case for Australia, New Zealand and Singapore.

The second insight is that it is abundantly clear that there exists no fantasy sports per se regulation in the Asia-Pacific region. This is not surprising given the similar regulatory environment up to 2018, which existed even in the industry's largest market of the USA. However, because fantasy sports is almost exclusively organized through the internet and thus online, many Asia-Pacific jurisdictions have enacted online gambling laws that may impact fantasy sports competitions. Only New Zealand allows offshore betting operators to take online bets (including online sports bets) onshore (although they cannot market their services onshore), while Australian law and Singapore law regulates (through state licenses) online sports betting within the country. Such a scenario offers fantasy sports operational security in the form of the Australian regulatory model. That is since sports betting is legal in these markets (albeit in limited number of sports) regulators can require fantasy sports operators to be licensed.

The third insight is that second largest potential sports betting and fantasy sports market in terms of consumer size-Indonesia (population of 300 million) — being a Muslim nation, does not currently allow any forms of gambling or onshore betting whatsoever. It would not be over zealous therefore, based on the market conditions elsewhere in the region, to state that offshore sports betting providers already have bridged the gap. Despite that, Indonesia may yet offer 
future opportunities for betting operators because of its unique political framework. While being the largest Muslim country in the world, Indonesia practices a moderate and tolerant form of Islam in most of its provinces ${ }^{79}$. The exception being the island of Sumatera, especially northern Sumatera where strict sharia law is enforced. Testimony to Indonesia's tolerance and respect for its ancient Hindu religious roots, the famed tourist island of Bali observes Hinduism as its official religion. Bali also has liberal laws for alcohol consumption (forbidden in Islam) and Western style tourism lifestyle. With future political will, perhaps Bali could host Indonesia's first legal sports betting and fantasy sports operator. An existing sports betting model (horse racing) has been in existence in neighboring Muslim Malaysia since 1957, which also is one of just four Muslim countries in the world that hosts casinos. ${ }^{80}$

The fourth insight is the support of sport governing bodies that can offer lower investment risks for online fantasy sports operators, where a jurisdiction does not license fantasy sports companies or either outlaws sports betting but the law for which is silent on fantasy sports competitions. Four national football governing bodies (China, South Korea, Japan and Australia) are already actively working with fantasy sports providers, and given their combined market sizes and formidable role in regional marketing rights agreements, there exists an opportunity for the regional football governing body - the Asian Football Confederation (AFC)— to take the lead in self-regulating football-based fantasy sports competitions. A parallel model known as sports integrity fees in sports betting as used in Australian sports could serve as an example for the $\mathrm{AFC}^{81}$. Australian sports betting operators pay national sports governing bodies an integrity fee for use of match data for gambling purposes (i.e., determining odds, publication of match results). This fee is utilized by the sports governing body to ensure corruption such as match fixing is strictly controlled in their leagues, which in turn protects the sports bettors' business model confidence with punters. Such market stakeholder-driven self-regulation may help lawmakers in the Asia-Pacific take regulatory risks or ease restrictions on fantasy sports competitions. The medium-term impact would be increased fan interest in the actual game. The AFC has trialed early moves with fantasy sports within its flagship Asian Cup championships ${ }^{82}$ but

\footnotetext{
79 Indonesia is an archipelago of 13,000 islands.

80 Ry 2013.

81 https://consultations.health.gov.au/national-integrity-of-sport-unit/ australian-sports-wagering-scheme-discussion-paper/supporting documents/Australian $\% 20$ Sports $\% 20$ Wagering $\% 20$ Scheme $\% 20 \%$ 20Discussion\%20paper.pdf.

82 Asian Football Confederation,https://www.the-afc.com/competitio ns/afc-asian-cup/news/afc-asian-cup-uae-2019-fantasy-football-goeslive Accessed 18 October 2020.
}

remains on the sidelines for further expansion of this strategy. This is contrast to its peers such as the European football governing body UEFA, which already actively promotes fantasy football using its own website. ${ }^{83}$

The fifth and final insight may appear obvious, that is the role of the mainland Chinese consumer in gambling and sports betting specifically. Our review in this paper has revealed that the gambling industries in Macau, Laos, Cambodia, Philippines and North Korea are directly dependent on Chinese gambling tourism. Further evidence from the Philippines, where Chinese gamblers can indirectly bet online, showcases the massive size of both legal and illegal online gambling in the Asia-Pacific. As such, the recent move by China to curtail gambling tourism activity of its citizens $^{84}$ may result in significant increase of illegal offshore online betting. While it remains unclear as to the share of sports betting in this pool, there remains a strong probability much of this gambling tourism wagers can be parlayed into illegal sports betting sites. What are the implications for fantasy sports operators? For one, with increased outflows to illegal online sites, regulators may turn extremely conservative to offer any concessions for fantasy sport that will create loopholes for illegal gambling. Second, forward-thinking regulators may sense an opportunity to channel these new wagers to fantasy sports competitions by enacting specific fantasy sports laws, which have curbs against pure chance like competitions.

\section{Regulatory framework for the Asia-Pacific fantasy sports market}

In this section, we return to the seven Nevada sports betting model regulatory best practices and consider the findings from our analysis. We then offer a regulatory framework for Asia-Pacific legislators and stakeholders:

\section{Integrity is paramount in the game; sports betting will fail if the game itself is riddled with integrity legacy issues}

We find Asia-Pacific is still a hotbed for global football match fixing ${ }^{85}$ despite a long history of such activities.

\footnotetext{
${ }_{83}$ UEFA https://gaming.uefa.com/en Accessed 16 October 2020.

${ }^{84}$ Kihara T, Nakano T and Onishi T, China's foreign casino ban risks snake eyes for Vietnam and rivals, Nikkei Asia (online), 7 September 2020. https://asia.nikkei.com/Business/Travel-Leisure/China-s-forei gn-casino-ban-risks-snake-eyes-for-Vietnam-and-rivals Accessed 18 October 2020.

${ }^{85}$ Costa 2018.
} 
International sports data company Sportradar reported 160 match fixing incidents in Asian football matches even during COVID-19 in $2020^{86}$. Therefore, sport governing bodies, in particular the Asian Football Confederation, need to improve its strategies to combat this malaise. Without confidence in the integrity of matches, lawmakers would be reluctant to approve sports betting and fantasy sports for the masses, if consumers are exposed to cheating on the field.

\section{State-level jurisdiction is supreme to federal level laws;}

Australia, Japan and China are the three jurisdictions that have both state (regional) and federal gambling laws. In the past (until 2016), regions in the Philippines also had the right to grant gaming licenses. State-level authority to grant gambling licenses has the advantage to meet local conditions and needs such as tax codes, local job creation, religious factors and political climate. State lawmakers are more in touch with public sentiment toward gambling in their local constituencies.

"Tax Rates and Fee Structures Can Dramatically Influence Both the Legal and Illegal Sports Betting Market." The price to enter the bet is an important consideration for punters to choose between using licensed bettors or illegal bettors.

In the Asia-Pacific, the lack of access to online legal sports betting is a very high opportunity cost to a punter. Therefore, thousands of illegal operators thrive in the market to fill the market need. This is the single biggest reason to legalize sports betting, by simply offering a legitimate product or service.

\section{“Government Mandates Are Not Necessary." Eco- nomics should dictate the relationship between sports governing bodies and sports betting operators}

Australia is the sole exception where the sport governing body and sports bettors entered into commercial contracts without government intervention. The political reality in countries such as China, Laos, Cambodia, Malaysia and the Philippines continue to see direct government intervention in commercial gambling mar-

\footnotetext{
$\overline{86}$ Careem N, South China Morning Post (online), 16 Feb 2021. https://www.scmp.com/sport/other-sport/article/3121904/match-fixing-160-suspicious-matches-asia-2020-covid-19-allows Accessed 1 June 2021.
}

kets. New market players would be cautious of making major investments in sports betting and fantasy sports infrastructure if such interventions take place despite existing legislation.

Illegal punters are here to stay, so enforcement must be ongoing despite regulation

There is strong enforcement evidence against illegal gambling in Malaysia, Singapore, China and Australia. The New Zealand model of approving offshore operators (legal and illegal) to offer online bets to locals is rather unusual and may actually deter predatory illegal operators. At the extremes, the Philippines regulation of licensing offshore operators to operate from the country (largely for China based punters) is another special business model that competes with illegal (non-licensed) offshore operators. The New Zealand and Philippines models are examples pre-emptive enforcement.

"Sports Wagering and Its Technology Needs to Maintain the Highest Standards of Integrity, Accountability, and Regulatory Compliance." There must be oversight in gaming infrastructure and technology to maintain confidence.

The Nevada model called for a comprehensive technology integrity at all levels of gambling especially with online gambling (or wagers taken outside the casino environment). The Nevada Gaming Commission (established in 1959) regulates technology in gambling. In our analysis, we did not encounter (other than a passing reference) a discussion on gambling technology in the Asia-Pacific. What we did find were the availability of many private proprietary fantasy sports platforms in Asia (for the Indian market) ${ }^{87}$, which raises the question: how as a regulator do you ascertain the credibility of these technologies?

Consumer gaming protection. There must be a comprehensive plan for problem gambling

Australia, New Zealand, Singapore and Japan have established strong and clear protection for problem gambling. The Japanese government, bowing to public pressure, even passed in 2018 the Specified Tourist Complex District Development Act (The Development

\footnotetext{
87 Casey, T, Fantasy sports trading platform Beryllium raises $\$ 3$ million in pre-series A funding, FORBES (online), 3 June 2021, https:// www.forbes.com/sites/timcasey/2021/06/03/fantasy-sports-tradingplatform-beryllium-raises-3-million-in-pre-series-a-funding/?sh= 15ac491d526e Accessed 13 June 2021.
} 
Act) to placate fears of negative consequences of its 2016 decision to allow casino licenses. However, our analysis revealed it is more self-regulation or "gambler-beware" policies in most other jurisdictions. To mitigate pushback from a wary Asia-Pacific public, legislators need to institute strong grassroots initiatives for problem gambling.

Given the complex level of action and regulation required to meet this best practice Nevada regulatory framework, we believe it would take a combination of political courage, change in public opinion, sport governing body co-operation, consumer demand, government tax revenue imperatives and industry lobby to achieve the end game. But the Asia-Pacific sports betting and fantasy sports market cannot afford to be a laggard market for years only because of weak regulation or even reluctance to legislate. Therefore, we suggest an interim regulatory strategy for sports betting and fantasy sports in the Asia-Pacific: Our analysis revealed that as of May 2021, 13 countries already license 178 land-based casinos in the Asia-Pacific enacting specific legislation such as those found in Macao, Singapore, Australia, Japan and the Philippines. This opens up opportunity to amend legislation to award sports betting licenses tied to these already strictly regulated existing casino licenses. Such a model was the one adopted by US states immediately after the 2018 Supreme Court ruling, and one that the Philippines has recently (December 2020) emulated for three of its land based casinos. Asia-Pacific regulators can replicate the US model and extend this by requiring the casino sports betting licensees to offer fantasy sports tournaments.

The strategy behind this suggested framework is to solve the "skill or chance conundrum" by having the same licensee (casino) to operate two different products-sports betting based on chance, and fantasy sports games based on skill. Since casinos need to collect athlete and sports team's statistical data to determine sports betting odds, they can offer these databases as a paid service to fantasy sports players. Many casinos also run onsite internet gambling devices so theoretically the infrastructure (gaming systems) can be scaled up to offer online sports betting and fantasy sports games.

Nevertheless, while encouraging the casinos to invest and offer fantasy sports platforms, to safeguard the risk of their monopolistic behavior, the exclusive fantasy sports licenses should have an expiry timeline of 5 to 10 years. This option serves both as a highly attractive windfall business opportunity for casinos to scale revenues, while regulators and lawmakers are able to immediately lower regulatory and policy risk of fantasy sports with a known entity (casino), which is incentivized to ensure strict compliance with the new rules. Further, gambling (sports betting) and entertainment (fantasy sports) taxation revenues for governments are centralized at the casino, significantly reducing tax collection risks.

\section{Future research agenda}

There was one critical finding from our analysis that warrants further scholarly research. This is the entry of blockchain technology that appears to have carved out a potential opportunity for fantasy sports providers to coexist within the current regulations. Blockchain offers winnings to be "paid" in alternate currency (e.g., bitcoins) rather than cash. In our analysis, the South Korean fantasy football venture with Sorare was an example. There have been similar such innovations in the Japanese and Chinese fantasy sports arena. In 2019, Japan's first fantasy sports company, NEO Sports, introduced a fantasy basketball league event called "Fantasy One" with winnings paid out in the form of gift vouchers. The Chinese Super League (CSL) football also teamed up with cryptocurrency player FootballCoin to offer blockchain technology-enabled fantasy sports. It should be noted that not all countries may be open to such innovation. For example in Australia, at least one jurisdiction (Northern Territory) outlaws blockchain payments in gambling. ${ }^{88}$ Scholar may wish to investigate how blockchain and cryptocurrencies will influence fantasy sports regulatory policy. How could blockchain regulation in turn impact the ability of fantasy sports rewards to offer bitcoins? Would regulators be less inclined to carve out exemptions for fantasy sports if blockchain technology was incorporated?

\section{Conclusion}

Fantasy sports regulation is non-existent in the Asia-Pacific markets with the exception of Australia. Until sports betting is widely accepted in the region, fantasy sport operators face uncertainty as to their legal status. This of course is similar to the predicament of fantasy sport industry giants FanDuel and Draft Kings during the early days of their launch in the US market. Our analysis provided insights on the possible application of existing regulation on fantasy sports

\footnotetext{
88 https://uk.practicallaw.thomsonreuters.com/w-022-4995?transition Type $=$ Default $\&$ contextData $=($ sc. Default $) \&$ firstPage $=$ true .
} 
and the path forward for stakeholders in the Asia-Pacific region. Lawmakers in the region need to recognize that fantasy sports promotes increased fan interest in real-life actual sports leagues. Legislators may want to study the Australian model of fantasy sports operator licensing as a compromise instead of the most favored current route of including fantasy sports under blanket laws for sports betting or banning interactive or online gambling. The state-by-state ongoing US legislation on sports betting (and fantasy sports) should be the least favored model for legislation since it continues the uncertain regulatory climate for the fantasy sports industry. Instead, the Nevada sports betting regulatory model should be the antecedents to a formidable fantasy sports regulation in the Asia-Pacific.

Funding There was no funding for this publication.

Data Availability All data have been referenced (footnotes) and publicly available

\section{Declarations}

Conflicts of interest There is no conflicts of interest

\section{References}

Aung A (2020) The International Politics of the Rohingya Crisis in Myanmar: China, Japan, and the United States. Kyoto Working Papers on Area Studies (134), 1-50.

Bünte M (2021) Ruling but not governing: Tutelary Regimes and the Case of Myanmar. Government and Opposition, 1-17.
Costa J (2018) The globalized network of a dirty game: match-fixing, illegal betting and transnational organized crime in Italian football. Global Crime 19(2):125-145

Das M (2018) International regulation of fantasy sports: comparative legal analysis of United States, Australian, and Asian Laws. UNLV Gaming Law J 8(2):3

Harris B (2020) Regulated Sports Betting: A Nevada Perspective. UNLV Gaming LJ 10:75

Hernandez-Diaz H (2020) Gaming in Japan: combating the fears and concerns of the people. UNLV Gaming Law J 10(2):5

McCartney GJ (2016) Play the cards, roll the dice - the integration of casinos within Asian tourism destination development strategy. UNLV Gaming Res Rev J 20(2):1-21

Pickering D, Blaszczynski A, Hartmann M, Keen B (2016) Fantasy sports: skill, gambling, or are these irrelevant issues? Curr Addict Rep 3:307

Ry KV (2013) Where Islam meets the West: a recommendation for the United Arab Emirates and Dubai in implementing casino-style gaming. UNLV Gaming Law J 4(1):6

Scott RA (2016) Updating your fantasy lineups and the federal law: the case for federal regulation of daily fantasy sports. Seton Hall L Rev 47:603

Sims K (2017) Gambling on the future: casino enclaves, development, and poverty alleviation in Laos. Pac Aff 90(4):675-699

Standen J (2016) The special exemption for fantasy sports, 42 N. Ky L Rev 427(433):436

Stokke K, Aung SM (2020) Transition to democracy or hybrid regime? the dynamics and outcomes of democratization in Myanmar. Eur J Dev Res 32(2):274-293

Yamada TS (2017) Phnom Penh's NagaWorld resort and casino. Pac Aff 90(4):743-765

Zabielskis P (2015) Too big to be bad? implications for theory and review of research on crimes, vices, and misdeeds in the casino culture of Macau. Crime Law Soc Chang 64(2-3):127-152

Zhang J (2017) Introduction: integrated mega-casinos and speculative urbanism in southeast Asia. Pac Aff 90(4):651-674

Publisher's Note Springer Nature remains neutral with regard to jurisdictional claims in published maps and institutional affiliations. 